Bangladesh J. Bot. 43(1): 79-86, 2014 (June)

\title{
GENE MINING: A CASE STUDY ON PUTATIVE IRON-RESPONSIVE CYANOBACTERIAL GENETIC LOCUS USING IN SILICO BIOINFORMATICS, ECOPHYSIOLOGY AND EXPRESSION-COMBINED APPROACH
}

\author{
NA El SemarY* \\ Department of Botany and Microbiology, Faculty of Science, Helwan University, \\ Ain Helwan Campus, Ain Helwan, Helwan, Egypt-11795
}

Key words: Bioinformatics, Ecophysiology, In silico, Iron, Phormidium-like cyanobacterium

\begin{abstract}
Gene mining is an advanced approach used for annotating genetic loci and assigning them a putative function. In that regard, a Phormidium-like cyanobacterium was initially tested positive for its ability to produce iron-chelators. To mine for the putative genetic locus associated with these iron-chelators, a combined bioinformatics, ecophysiological, molecular and expression approach was applied. In order to test for the influence of iron limitation/starvation on the putative gene(s) involved, different levels of iron limitation/starvation were applied and the expression was quantified using real-time PCR. Mild iron limitation induced the expression of this iron-responsive locus at the beginning of iron stress but no detectable levels of expression were found as the stress continued. This possibly indicates the "switch off" of this putative genetic locus under conditions of extreme iron starvation. This locus is most likely involved in the synthesis of a membrane-associated protein that mediates iron transport or binding across membrane.
\end{abstract}

\section{Introduction}

Iron is an essential element for many cellular processes (Miethke et al. 2006). The iron requirement by cyanobacteria is much higher than that of eukaryotic algae due to the high iron demand of the former's photosynthetic system (Brand 1991). Interestingly, cyanobacteria developed different strategies to meet their high iron demand. For example, they act as biological sorbents for dissolved metal ions including iron (Dittrich and Sibler 2005) and therefore they dominate aquatic environments contaminated by inorganic and organo-metallic chemicals (Baptista and Vasconcelos 2006). Cyanobacteria can also overcome the deficiency in available iron in culture medium through the production of iron chelators that can chelate both adsorbed and/or bound iron (Wilhelm 1995b). This allows the uptake of iron needed to meet the high demand of cyanobacteria (Brand 1991). In all cases, the ability of producing, regulating and varying the expression of iron uptake systems undoubtedly gave the cyanobacteria an ecological advantage over other aquatic organisms and helped them dominate their niches (Ferreira and Straus 1994). The iron chelators synthesis is mediated by the activity of NRPS and PKS genetic systems (Ehrenreich et al. 2005). Nevertheless, not much is known about the specific number, arrangement and expression of the genes responsible for iron uptake in different cyanobacterial taxa. In our case, it is not clear how the iron limitation would affect growth of an isolate that once lived in luxury of iron in its vicinity and what genes might be responsive to such environmental signalling. Fortunately, the identification of genetic loci responsible for certain signal transduction or production of a certain metabolite in response to a specific factor in a given microorganism, is greatly facilitated by in silico analysis of closely related genetic loci and the design of degenerate

*Author for correspondence.<nerminel_semary@yahoo.co.uk>. 
primers. This bioinfoamtic approach was successfully used (Ehrenreich et al. 2005, Barrios et al. 2007) as a mining tool for searching for cyanobacterial genes active in secondary metabolite production. In this study, our main focus is on searching for an iron-responsive genetic locus (Rodon et al. 2004, Ehrenreich et al. 2005) as well as investigating how iron deficiency affects the expression of this putative iron-responsive genetic locus. To address these points, the Phormidium-like cyanobacterium will be exposed to different treatments of iron limitation/ starvation under different environmental conditions (light/temperature) during certain time course using real-time PCR. This approach is particularly useful in cases where the expression of a genetic locus is directly linked to the physiological status due to certain environmental conditions. Those conditions can act either as a stimulus or inhibitor for gene expression. To allow for testing for the presence of iron responsive gene(s), physiological and molecular studies on the effect of iron limitation on this cyanobacterium were performed.

\section{Materials and Methods}

Monospecific cultures of Phormidium-like cyanobacterium were grown at $30{ }^{\circ} \mathrm{C}$ and 20 $\mu \mathrm{mole} / \mathrm{m}^{2} / \mathrm{s}$. Iron chelators production was assayed using the chrome azural S (CAS) liquid assay (Schwyn and Neilands 1987). Molecular analysis of cultures involved the following:

(1) Initial screening: The primers designed by Ehrenreich et al. (2005) were used to allow for screening for the presence of genes responsible for iron chelators, namely NRPS; (MTF2 (5'GCNGGYGGYGCNTAYGTN CC-3') and MTR (5'-CCNCGDATYTTNACYTG-3') and PKS; DKF(5'-GTGCCGGTNCCRTGN GYYTC-3)and DKR (5'-GCGATGGAYCCNCARCARYG-3').

(2) The design of primers for putative iron-responsive genetic locus: Rodon et al. (2004) reported that the part of the gene cluster responsible for iron uptake system in Agrobacterium tumefaciens showed the highest similarity to un-annotated open reading frame within the genome of Nostoc PCC 7120, and attributed this to the similarity of function. We used this open-reading frame within the Nostoc PCC 7120 (all2646) and compared it to other genetic loci from different cyanobacterial groups, through BLAST search. The genes involved in the alignment were used for the design of primers and the accession numbers are listed in Table 1. However, the similarity at the protein level was much higher than that at the nucleotide level and thus the primers designed were degenerate.

Table 1. The cyanobacterial taxa and their genetic loci used in the alignment for designing putative iron-responsive degerate primers.

\begin{tabular}{lcl}
\hline Organism & Accession number & Protein ID \\
\hline Nostoc sp. PCC 7120 & BA000019.2 & all4626 \\
Lyngbya majuscula & AY522504.1 & JamP, AAS98781 \\
Anabaena variabilis ATCC & CP000117.1 & Beta-ketoacyl synthase \\
Nostoc sp. GSV224 & AF204805.2 & Nos B, polyketide synthase type I \\
Lyngbya majuscula strain 19L & AY652953 & Cur A, AAT70096 \\
Lyngbya majuscula & AF5598782 & Jam K \\
Aphanizomenon ovalisporum & AF395828.1 & aoa peptide synthetase, AAM3346810 \\
Microcystis aeruginosa & AB032549.2 & BAB12210 \\
Nodularia spumigena strain NSOR10 & AY210783.2 & NdacAAO64404 \\
Planktothrix agardhii NIVA-CYA126/8 & AJ441056.1 & Peptide synthetase CAD29795 \\
\hline
\end{tabular}


This necessitated the design of two forward primers (used in equimolar concentration) to cover the taxa used in alignment.

$$
\begin{aligned}
& \text { sdfor1:5'-GA(CT)GG(N)C(AG)(CT)TG(CT)(AG)C(AGCT)TT(CT)GA-3'; } \\
& \text { sdfor2: 5'-GA(CT)GGN(AC)G(AG)TG(CT)(AG)CNTT(CT)GA-3'. } \\
& \text { sdrev: 5'-CCNCT(CT)AT(AG)C(AG)NCGNCGNTG-3'. }
\end{aligned}
$$

(3) PCR. The two NRPS and PKS genetic loci were initially amplified using SuperTaq polymerase enzyme with SuperTaq buffer without additional $\mathrm{Mg}^{++}$. The primers designed by Ehrenreich et al. (2005) were used. The reactions contained either $2 \mu \mathrm{l}$ of genomic DNA or $4 \mu \mathrm{l}$ of filament lysate in $1 \mathrm{x}$ buffer as a template. Amplification protocols for all the loci mentioned above are summarised in Table 2. Gradient PCRs were conducted for all loci tested without changing the initial and final cycles but with modifying the annealing temperatures between $49-60^{\circ} \mathrm{C}$ for thirty seconds when necessary on a gradient PCR thermal cycler (G storm, UK). PCR products were

\begin{tabular}{|c|c|c|c|}
\hline \multirow[t]{2}{*}{ Locus } & \multicolumn{3}{|c|}{ PCR conditions } \\
\hline & Initial & Main & Final \\
\hline PKS & $94^{\circ} \mathrm{C}, 5 \mathrm{~min} \times 1$ cycle & $\begin{array}{l}94^{\circ} \mathrm{C}, 1 \mathrm{~min} ; 50^{\circ} \mathrm{C}, 1 \mathrm{~min} ; 72^{\circ} \mathrm{C}, 1 \mathrm{~min} \times 35 \\
\text { cycle }\end{array}$ & $72^{\circ} \mathrm{C}, 7 \mathrm{~min} \times 1$ cycle \\
\hline Gradient & The same as above & $\begin{array}{l}94^{\circ} \mathrm{C}, 1 \mathrm{~min} ;\left(49-60^{\circ} \mathrm{C}, 30 \mathrm{sec}\right) ; 72^{\circ} \mathrm{C}, 1 \mathrm{~min} \\
\times 35 \text { cycle }\end{array}$ & The same as above \\
\hline NRPS & $94^{\circ} \mathrm{C}, 5 \mathrm{~min} \times 1$ cycle & $\begin{array}{l}94^{\circ} \mathrm{C}, 1 \mathrm{~min} ; 50.8^{\circ} \mathrm{C}, 1 \mathrm{~min} ; 72^{\circ} \mathrm{C}, 1 \mathrm{~min} \times \\
35 \text { cycle }\end{array}$ & $72^{\circ} \mathrm{C}, 7 \mathrm{~min} \times 1$ cycle \\
\hline Gradient & The same as above & $\begin{array}{l}94^{\circ} \mathrm{C}, 1 \mathrm{~min} ;\left(49-60^{\circ} \mathrm{C}, 30 \mathrm{sec}\right) ; 72^{\circ} \mathrm{C}, 1 \mathrm{~min} \\
\times 35 \text { cycle }\end{array}$ & The same as above \\
\hline New PKS & $94^{\circ} \mathrm{C}, 3 \mathrm{~min} \times 1$ cycle & $\begin{array}{l}94^{\circ} \mathrm{C}, 1 \mathrm{~min} ; 57^{\circ} \mathrm{C}, 1 \mathrm{~min} ; 72^{\circ} \mathrm{C}, 1 \mathrm{~min} \times \\
35 \text { cycles }\end{array}$ & $72^{\circ} \mathrm{C}, 7 \mathrm{~min} \times 1$ cycle \\
\hline Gradient & The same as above & $\begin{array}{l}94^{\circ} \mathrm{C}, 1 \mathrm{~min} ;\left(49-60^{\circ} \mathrm{C}, 30 \mathrm{sec}\right) ; 72^{\circ} \mathrm{C}, 1 \\
\min \times 35 \text { cycle }\end{array}$ & The same as above \\
\hline
\end{tabular}
either directly purified or ligated into the $\mathrm{TOPO}^{\circledR} 4.1$ vector for transformation and sequencing.

Table 2. Primers and PCR conditions for the genetic loci amplification.

Eco-physiology and gene expression experiments involved the following:

(1) Different iron limitation/starvation levels and total RNA extraction: To test whether the genetic locus amplified by our newly-designed primers is an iron responsive one, an experiment was conducted using Phormidium-like cyanobacterium under different levels of iron deficiency/starvation. The experiment involved two groups of treatments; one included the Oscillatoria growth medium with the iron fraction added (iron-replete, $+\mathrm{Fe}$ ) and the other involved the same medium but with the omission of the iron fraction (iron-deficient, $-\mathrm{Fe}$ ). The two treatments were inoculated with thick mid-log phase inoculum and left to grow at room temperature (approximately $30{ }^{\circ} \mathrm{C}$, light intensity $20 \mu \mathrm{mol}$ photon $/ \mathrm{m}^{2} / \mathrm{s}$ ). After four days, $20 \mathrm{mM}$ dipyridyl was added to two flasks $(50 \mathrm{ml})$ of each treatment to act as iron chelator and induce iron stress. This concentration is the highest in effectively scavenging any iron trace (Rodon et al. 2004). The total RNA was extracted from the initial treatments i.e. $+\mathrm{Fe}$ and $-\mathrm{Fe}$ before the addition of DIP and later every two days after its addition, for the four treatments $(+\mathrm{Fe}$ and $-\mathrm{Fe}$, $+\mathrm{Fe}+\mathrm{DIP}$ and $-\mathrm{Fe}+\mathrm{DIP}$ ), using tripure kit (Boehringer Mannheim, Germany). The extracted RNA was dissolved in $15 \mu 1$ sigma water and the concentration of the total RNA was directly estimated using Nanodot spectrophotometer, UK at $260 \lambda$. (2) Effect of DIP dilutions on the expression of 
the genetic locus: Two different concentrations of DIP were later used i.e. $20 \mu \mathrm{M}$ and $200 \mu \mathrm{M}$ in a separate experiment on iron-replete $(+\mathrm{Fe})$ and iron-deficient $(-\mathrm{Fe})$ cultures to compare the effect of DIP dilutions on the expression of the putative iron-responsive gene. The total RNA was extracted after two days of the treatments.

(3) Effect of temperature on the expression: To test the effect of the decrease in temperature on the expression of the putative iron-responsive genetic locus, three cultures of every treatment ( $+\mathrm{Fe}$ and $-\mathrm{Fe}$, no DIP is applied) were incubated at growth temperature of $15^{\circ} \mathrm{C}$ for two days before the extraction of total RNA.

DNAse treatment: In order to breakdown any genomic DNA that may be contaminating the RNA preparations, the samples containing $1.5 \mu \mathrm{g}$ total RNA were treated with DNAse, Promega, USA, and its buffer at final concentrations of $100 \mathrm{U}$ and $1 \mathrm{x}$, respectively in total volume $20 \mu \mathrm{l}$ and the mixture was incubated at $37^{\circ} \mathrm{C}$ for $30 \mathrm{~min}$. The reaction was terminated using $3 \mu 1$ stop solution (20 mM EGTA, Promega, USA). The assays were incubated for another $10 \mathrm{~min}$ at $65^{\circ} \mathrm{C}$ to inactivate the DNAse and the purified RNA was a template for complementary DNA (cDNA) synthesis. The cDNA synthesis mixture included: $7.5 \mu 1$ of DNAse-treated RNA mixed with $7.5 \mu 1$ of $15 \mu \mathrm{M}$ siderophore rev primer, $0.2 \mu \mathrm{l}$ of TRAFF rev primer, $0.3 \mu \mathrm{l}$ of $3 \mathrm{ng}$ of mRNA of TRAFF spike (tumour recognition factor, used as an internal indicator for the efficiency of reverse transcriptase reaction (Wilson et al. 2004), mixed at $70^{\circ} \mathrm{C}$ for $4 \mathrm{~min}$, cooled down to $60^{\circ} \mathrm{C}$ for one min and then kept on ice until $14.5 \mu \mathrm{l}$ of a master mix containing the following components was added: $6 \mu 1$ 5x M-MLV reverse transcriptase reaction buffer (Promega), 24 units Rnasin ${ }^{\circledR}$ ribonuclease inhibitor (Promega), $1.25 \mathrm{mM}$ dNTP, 40 units of dithiothreitiol (Sigma) and 300 units of M-MLV reverse transcriptase (Promega). The reactions were incubated at $42{ }^{\circ} \mathrm{C}$ for $1 \mathrm{hr}$. Two control assays contained the same components but one without reverse transcriptase and the other one without DNAse-free RNA. Conventional PCRs were performed to verify the success of the reverse transcription reaction in synthesizing cDNA. The PCR included two sets; a set using the iron-respoive degenerate primers and the other set using the TRAFF primers and in both sets, 1 $\mu \mathrm{l}$ of the cDNA was the template. The $25 \mu 1$ reaction contained $1 \mathrm{x}$ Promega Taq buffer, $0.5 \mathrm{U}$ of Promega Taq, $200 \mu \mathrm{M}$ dNTPs and $15 \mu \mathrm{M} \mathrm{MgCl}_{2}$.

Real-time PCR: Twenty $\mu 1$ assays contained: $9 \mu 1$ template and $11 \mu \mathrm{l}$ containing mixture of $300 \mu \mathrm{M}$ of each primer and the components of SybrGreen PCR core reagents (Applied biosystems): 0.25 units AmpliTaq Gold DNA polymerase, 0.1 units AmpErase UNG, $200 \mu \mathrm{M}$ dATP, dCTP, dGTP; $400 \mu \mathrm{M}$ dUTP, $3 \mathrm{mM} \mathrm{MgCl}, 1 \mu \mathrm{l} 10 \times$ SYBR Green buffer. For real-time monitoring of the fluorescence increases during the exponential stage of the PCR, sequence detection system 7000 (Applied biosystems) was used. The assays were subjected to a thermal programme as follows: $50^{\circ} \mathrm{C}, 2 \mathrm{~min} \times 1$ cycle, $95^{\circ} \mathrm{C}, 10 \mathrm{~min} \times 1$ cycle, then 45 cycles of $94^{\circ} \mathrm{C}$ for $1 \mathrm{~min}, 57^{\circ} \mathrm{C}$ for $1 \mathrm{~min}$ and $72^{\circ} \mathrm{C}$ for $1 \mathrm{~min}$. The programme was terminated by a dissociation analysis in order to determine the negative change in fluorescence due to melting of the amplicons. The controls included water controls, DNAse-treated RNA of four samples without reverse transcriptase and a gradient concentration of bluescript plasmid vector $(10,1,0.1,0.01$ picogram). Three master mixes were prepared for the first real time PCR: Mastermix for the cDNA samples with the iron-chelators primers and the SybrGreen PCR core reagents and the second was for cDNA samples with TRAFF primers and the core reagents and the third for standards with M13 forward and reverse primers with the rest of PCR reagents. The templates for the first real time PCR were diluted cDNAs (1: 4.5 dilutions, i.e. $8 \mu \mathrm{l}$ cDNA plus $28 \mu 1$ Sigma water). Different dilutions of the cDNAs were also tested. 


\section{Results and Discussion}

Initially, primers proposed by Ehrenreich et al. (2005) were tested on the isolate understudy and other cyanobacteria. The PKS primers failed to amplify our isolate and all other isolates tested. On the contrary the NRPS primers positively amplified a 'ladder' of products in both Nodularia and Planktothrix with a very clear top band of approximate size of 1000 bp. Nostoc 6718 and Aphanizomenon ovalisporum both gave single product of approximate size of 500 bp but failed to amplify any of the Egyptian culture collection (Table 3). The NRPS amplicons for Nodularia were cloned and only one clone was sequenced (Accession number, EF090964) which showed no resemblance to any sequences except for a weak resemblance to Leptolyngbya (maximum coverage of resemblance is $5 \%$ throughout its entire length to other cyanobacterial genera). The amplification of putative iron responsive genetic loci was performed through the use of our iron-responsive degenerate primers gave positive two bands with our isolate: one of the size

Table 3. The isolates used for testing NRPS and PKS primers.

\begin{tabular}{llll}
\hline Isolate & Growth conditions and growth medium & NRPS & PKS \\
\hline $\begin{array}{l}\text { Spirulina } \\
\text { Nostoc } 6718\end{array}$ & $15^{\circ} \mathrm{C}$, dim light (Bristol collection), Spirulina medium, & - & - \\
$\begin{array}{l}\text { Aphanizomenon } \\
\text { ovalisporum }\end{array}$ & $15^{\circ} \mathrm{C}$, dim light, $\mathrm{BG}_{11}$ medium & + & - \\
$\begin{array}{l}\text { Synechocystis } \\
\text { Nodularia }\end{array}$ & Room temperature, dim light, , $\mathrm{BG}_{11}$ medium & + & - \\
$\begin{array}{l}\text { Planktothrix cya137 } \\
\text { Phormidium-like }\end{array}$ & $15^{\circ} \mathrm{C}$, dim light, $\mathrm{MN}$ medium , very dim light, Oscillatoria medium & - & - \\
$\begin{array}{l}\text { cyanobacterium } \\
\text { Leptolyngbya } \\
\text { cyanobacterium }\end{array}$ & Room temperature, dim light, Oscillatoria medium & + & - \\
\hline
\end{tabular}

$400 \mathrm{bp}$ and the other of the size $575 \mathrm{bp}$. The latter product whose expression was later detected by real-time PCR was sequenced and deposited in the Genbank (Accession number EU624395). Regarding the expression experiments, the standard curve established for the Real-time PCR is found in Fig. 1. TRAFF conventional PCR was successful for all samples, thus indicating the success of the reverse transcription reaction. The only cDNA sample that positively amplified the right-sized amplicon (575 bp) in the conventional PCR, was synthesized from the RNA extracted from the treatment of $+\mathrm{Fe}+\mathrm{DIP}$ on $10 / 8$ after two days of the addition of $20 \mu \mathrm{M}$ DIP. The DNA molecules that resulted from real-time PCR was cloned and sequenced to confirm its identity and its similarity to the product obtained in the conventional PCR. None of the other treatments (dilutions of DIP or the decrease in temperature) gave detectable bands. The three-fold dilution of cDNA samples proved to be the best detectable level. The mean relative transcript abundance after normalizing the data was $5.68 \times 10^{-5}$ An initial nucleotide BLAST search in the cyanobacterial sequences revealed high similarities to the cloned product but with partial coverage to genomic regions within several cyanobacterial taxa with statistical significance as indicated from higher stringency indicated by $\mathrm{E}$ value (Table 4). E value is the expectation value which signifies the statistical significance for matches against database sequences. Lower EXPECT thresholds are more stringent (http://genome.microbedb.jp/blast/blast_search/ cyanobase/genes). The comparison of the sequence of the amplicon retrieved from Phormidium-like cyanobacterium after translation, with the BLAST-protein database revealed its slight similarity to ATP-binding region, ATPase- 
like histidine kinase A of Crocosphaera watsonii WH 8501 with score $32.3 \%$ and Trichodesmium erythreum TonB periplasmic protein (TonB, links inner and outer membranes) with score $28.5 \%$. A more specific search using cyanobase database which encompasses database about the cyanobacterial genomic projects (http://genome. microbedb.jp/blast/blast_search/cyanobase/ genes). Similarities to several $\mathrm{ABC}$ transporters and zinc/iron permease were revealed (Table 5).

Table 4. The nucleotide BLAST search for sequence similarities for the putative iron responsive genetic locus.

\begin{tabular}{|c|c|c|c|c|}
\hline $\begin{array}{l}\text { The accession } \\
\text { number }\end{array}$ & The name of organism & $\begin{array}{c}\text { The identity } \\
(\%)\end{array}$ & $\begin{array}{l}\mathrm{E} \\
\text { value }\end{array}$ & $\begin{array}{c}\text { The coverage } \\
(\%)\end{array}$ \\
\hline СР001842.1 & Cyanobacterium UCYM-A complete genome & 69 & $3 e-08$ & 28 \\
\hline СР00129.1 & Cyanothece sp. PCC7424 complete genome & 77 & $4 \mathrm{e}-06$ & 12 \\
\hline СР003620.1 & $\begin{array}{l}\text { Crinalium episammum PCC9333 complete } \\
\text { genome }\end{array}$ & 82 & $7 \mathrm{e}-04$ & 13 \\
\hline
\end{tabular}

Table 5. Sequence similarity search using Cyanobase database (http://genome.microbedb.jp/blast/ blast_search/cyanobase/genes)

\begin{tabular}{llc}
\hline Genetic locus & Annotation & Coverage (\%) \\
\hline slr0615 & ATP-binding protein of ABC transporter & 36 \\
slr0369 & RND multidrug efflux transporter & 36 \\
Npun_R2836 & hypothetical protein & 34 \\
Cyan7425_1370 & signal transduction histidine kinase & 34 \\
PCC7424_2509 & zinc/iron permease & 34 \\
\hline
\end{tabular}

The treatment with the very high concentration of DIP, i.e. $20 \mathrm{mM}$, made the iron limitation quite drastic and the change was easily observed. Bleaching and death of cells was at its highest in $\mathrm{Fe}+\mathrm{DIP}$, with less but still drastic effect in $+\mathrm{Fe}+\mathrm{DIP}$. In case of $-\mathrm{Fe}$ treatments, mats remained viable for a while which is possibly attributable to the presence of minor iron traces either in glassware, other components of medium and within the original inoculum itself. Also, the fact that Phormidium-like cyanobacterium is mat-forming, and that the anoxic microenvironment within the mat itself may prevent the oxidation of any traces of soluble Fe (II) may also explain the less drastic effect of $-\mathrm{Fe}$ on growth of culture than that of $-\mathrm{Fe}+\mathrm{DIP}$. The expression of the putative iron-responsive genetic locus seems to be related to the level of iron stress. At the beginning of the experiment, the expression of this gene is neither detected in $+\mathrm{Fe}$ nor in -Fe treatment. As DIP is applied in a very high concentration, i.e. $20 \mathrm{mM}$, the expression of this gene is at its highest detectable levels after two days of inducing mild iron-stress at the beginning $+\mathrm{Fe}+\mathrm{DIP}$ treatment but as the experiment proceeded, this treatment eventually lead to cell death. This is in contrast to the $-\mathrm{Fe}+\mathrm{DIP}$ treatment where no expression of this gene was detectable throughout the experiment. Those results can be explained in the light of the fact that cyanobacteria have the ability to accumulate, detoxify or metabolise metallic contaminants (Garcia-Meza et al. 2005). Thus, the presence of iron-responsive genes in cyanobacterial strains inhabiting an industriallypolluted habitat is largely expected. The nature of these iron responsive genes in our cyanobacterial isolate is not known. As an initial investigation, we used the primers designed by Ehrenreich et al. (2005) reported to amplify genes responsible for iron chelators synthesis from diverse groups of cyanobacteria to explore the presence of iron-responsive genes. Unlike what was expected, they failed to amplify with our isolates and most of the isolates tested especially those 
used to amplify PKS genetic loci. This indicates that those genes are not conserved even within the same genus and that the ability to produce secondary products, including iron chelators, can be strain-specific (Rodon et al. 2004). On the other hand, the newly-designed primers based on homology to putative iron-responsive genetic locus were successful in amplifying with our isolate. Baptista and Vasconcelos (2006) reported that A P-type ATPase is a ubiquitous membrane transporter that carries metal ions. They differentiate into five major branches: type I, II, III, IV and V ATPases (heavy metal pumps). Some of those types are reported in cyanobacteria although not fully investigated. However, Tong et al. (2002) reported the existence of a novel histidine-rich CPx-ATPase from the filamentous cyanobacterium Oscillatoria brevis related to multiple-heavy metal co-tolerance. For many elements, there is evidence that bacteria control their metal requirements by the expression of metalloproteins. Metal-responsive transcriptional regulators modulate expression of the genes encoding metal ion binding and/or transport proteins according to the respective substrate concentration (Cavet et al. 2002). Thus, the locus identified, is most likely involved in the synthesis of a membrane associated protein that mediates iron transport or binding across membrane. Nevertheless, it seems that this iron-responsive genetic locus is not expressed under conditions of complete iron-starvation where this condition only leads to rapid cell death and shutting down metabolism (Ferreira and Straus 1994). Interestingly, the use of

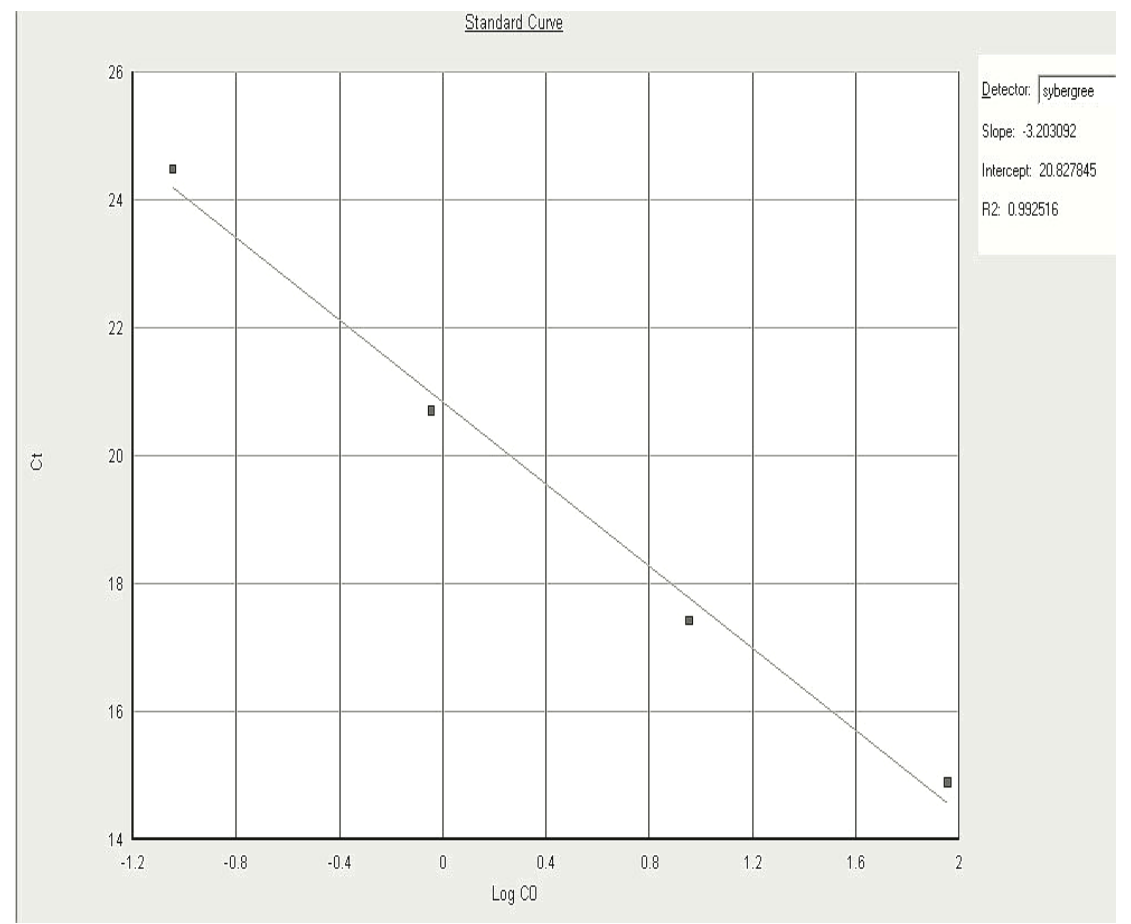

Fig. 1. The standard curve of $\mathrm{Ct}$ value against the logarithmic concentrations of the serially-diluted plasmidcontaining insert standard.

lower DIP concentrations did not induce the expression of iron-responsive genetic locus after two days of the treatment. This is not surprising since in case of treatment $+\mathrm{Fe}$ with low DIP concentrations, no real iron stress is induced in contrast with $-\mathrm{Fe}+\mathrm{DIP}$ treatment, where low DIP concentration would scavenge the minor iron traces present. Similarly, the low temperature 
treatment did not induce the expression of iron responsive genetic locus. To sum up, the expression of the iron-responsive genetic locus seems to be detectable during the beginning of the iron limitation period for a short period. This only reflects that the iron-transport capability is increased in response to iron limitation but not under prolonged iron starvation that leads to the shutting off metabolic activities and cell death.

\section{References}

Baptista MS and MT Vasconcelos 2006. Cyanobacteria metal interactions: requirements, toxicity, and ecological implications. Cri. Rev. Microbiol. 32: 127-137.

Barrios-Llerena ME, AM Burja and PC Wright 2007. Genetic analysis of polyketide synthase and peptide synthetase genes in cyanobacteria as a mining tool for secondary metabolites. J. Ind. Microbiol. Biotechnol. 34: 443-456.

Brand LE 1991. Minimum iron requirements of marine phytoplankton and the implications for the biogeochemical control of new production. Limnol. Oceanogr. 36: 1756-1771.

Cavet JS, W Meng, MA Pennella, RJ Appelhoff, DP Giedroc and NJ Robinson. 2002. A nickel-cobaltsensing ArsR-SmtB family repressor: contributions of cytosol and effector binding sites to metal selectivity. J. Biol. Chem. 277: 38441-38448.

Dittrich M and S Sibler, 2005. Cell surface groups of two picocyanobacteria strains studied by zeta potential investigations, potentiometric titration, and infrared spectroscopy. J. Colloid Interface Sci. 286: 487-495.

Ferreira F and N Straus 1994. Iron deprivation in cyanobacteria. J. Appl. Phycol. 6: 199-210.

Ehrenreich IM, JB Waterbury and EA Webb 2005. Distribution and diversity of natural product genes in marine and freshwater cyanobacterial cultures and Genomes. Appl. Environ. Microbiol. 71(11): 74017413.

Garcia-Meza JV, C Barrangue and W Admiraal 2005. Biofilm formation by algae as a mechanism for surviving on mine tailings. Environ. Toxicol. Chem. 24(3): 573-581.

Miethke M, P Bisseret, CL Beckering, D Vignard, J Eustache and MA Marahiel 2006. Inhibition of aryl acid adenylation domains involved in bacterial siderophore synthesis. FEBS J. 273: 409-419.

Rondon MR, KS Ballering and MG Thomas 2004. Identification and analysis of a siderophore biosynthetic gene cluster from Agrobacterium tumefaciens C58. Microbiology. 150: 3857-3866.

Schwyn B and JB Neilands 1987. Universal chemical assay for the detection and determination of siderophores. Ann. Biochem. 160: 47-56.

Tong L, S Nakashima, M Shibasaka, M Katsuhara, K Kasamo 2002. A novel histidine-rich CPx-ATPase from the filamentous cyanobacterium Oscillatoria brevis related to multiple-heavy metal coolerance. J. Bacteriol. 184: 5027-5035.

Wilhelm SW 1995b. Ecology of iron-limited cyanobacteria: A review of physiological responses and implications for aquatic systems. Aqu. Microbial Ecol. 9: 295-303Publishing, Ltd.

Wilson ID, GLA Barker, RW Beswick, SK Shepherd, C Lu, JA Coghill, D Edwards, P Owen, R Lyons, JS Parker, JR Lenton, MJ Holdsworth, PR Shewry and Edwards KJ 2004. A transcriptomics resource for wheat functional genomics. Plant Biotechnol. J. 2: 495-506.

(Manuscript received on 4 March, 2013; revised on 11 December, 2013) 